\title{
Femoral access site closure without prior femoral angiography
}

\section{A retrospective analysis}

\author{
Christoph Brenner · Julian Margreitter · Alexandra Gratl · Josef Klocker · Rudolf Kirchmair · Peter Marschang · \\ Guy Friedrich · Bernhard Metzler · Nicolas Moes
}

Received: 19 February 2017 / Accepted: 6 January 2018 / Published online: 24 January 2018

(C) The Author(s) 2018. This article is an open access publication.

\begin{abstract}
Summary
Aims and background Although guideline recommendations have shifted towards a transradial route, femoral puncture is still an established vascular access, especially for complex coronary interventions. The FemoSeal ${ }^{\mathrm{TM}}$ vascular closure device (FVCD) helps to reduce femoral compression time and access site complications after removal of the catheter sheath. To ensure safe use, an angiography of the femoral artery prior to FVCD deployment is recommended by the manufacturer. We postulate that omitting this angiography does not relevantly increase the risk for vascular complications.

Methods and results In this retrospective analysis of an all-comers population ( $n=1923)$ including patients receiving a percutaneous coronary intervention (PCI), we could show that combined vascular complication rates without femoral angiography were low (primary endpoint $4.6 \%$ ) and comparable to a randomized clinical trial that did perform angiography of the vascular access site in a cohort of patients receiving diagnostic coronary angiography only. In addition to this analysis, we could demonstrate that patients with an acute coronary syndrome, receiving periprocedural anticoagulation or anti-platelet therapy had an increased risk for the formation of arterial pseudoaneurysms;
\end{abstract}

C. Brenner, MD (西) · J. Margreitter · R. Kirchmair, MD . P. Marschang, MD · G. Friedrich, MD · B. Metzler, MD · N. Moes, MD

Department of Internal Medicine III, Cardiology and Angiology, Medical University of Innsbruck,

Anichstr. 35, 6020 Innsbruck, Austria

mail@med.cbrenner.net

A. Gratl, MD · J. Klocker, MD

Department of Vascular Surgery, Medical University of Innsbruck, Innsbruck, Austria however, we did not observe any ischemic vascular event after FVCD deployment.

Conclusion Closure of the femoral access site after coronary angiography using the FVCD can be safely performed without femoral angiography; however, due to an increased risk for the formation of pseudoaneurysms we recommend the transradial access in situations with increased bleeding risk.

Keywords Radiation protection - Cost-benefit analysis - Vascular system injuries - Cardiac catheters . Safety

\begin{tabular}{|c|c|}
\hline \multicolumn{2}{|c|}{ Abbreviations } \\
\hline AA & $\begin{array}{l}\text { Periprocedural anticoagulation and anti- } \\
\text { platelet therapy }\end{array}$ \\
\hline ACS & Acute coronary syndrome \\
\hline CAG & Coronary angiography \\
\hline $\mathrm{F}$ & French (0.33 millimeter) \\
\hline FVCD & $\begin{array}{l}\text { FemoSeal }{ }^{\mathrm{TM}} \text { vascular closure device, manu- } \\
\text { factured by St. Jude Medical }\end{array}$ \\
\hline GFR & Glomerular filtration rate \\
\hline IQR & Interquartile range \\
\hline $\mathrm{PA}$ & Pseudoaneurysm \\
\hline $\mathrm{PAD}$ & Peripheral artery disease \\
\hline VCD & Vascular closure device \\
\hline
\end{tabular}

\section{Introduction}

Despite increasing rates of radial access for percutaneous coronary angiography, the femoral vascular access site is still frequently used, especially for complex coronary interventions with use of larger guiding catheters [1]. In previous analyses total vascular complication rates (bleeding and other vascular complications) after femoral puncture for percutaneous interventions ranged from $2 \%$ to $7.9 \%$ after manual 
compression for closure of the vascular entry site [2, 3].

The FemoSeal ${ }^{\mathrm{TM}}$ vascular closure device (FVCD) has been introduced to reduce femoral compression time and access site complications after removal of the catheter sheath $[3,4]$. Previous clinical trials have suggested that the use of VCD may be associated with a slight increased risk for limb ischemia. Vascular stenoses or arterial embolization induced by the FVCD can lead to a critical reduction of blood flow with subsequent need for vascular surgery. Therefore, an angiography of the ipsilateral common femoral artery is recommended by the manufacturer before deployment of the FVCD [5]. This helps to ensure that the femoral artery (1) has a sufficient lumen diameter of $\geq 5 \mathrm{~mm} \mathrm{(2),} \mathrm{no} \mathrm{relevant} \mathrm{stenosis,} \mathrm{atherosclerotic}$ plaques or vascular abnormalities at the puncture site and that (3) the arterial puncture is not located at or distal to the common femoral artery bifurcation; however, in high-volume centers frequently using the transfemoral approach for coronary angiography, the final femoral angiogram is time-consuming, can lead to a relevant additional radiation exposure for physicians and an increased consumption of the costintensive and nephrotoxic contrast agent.

In our center, we generally deploy the FVCD without a prior femoral angiogram. In this study we quantified vascular access site complications resulting from femoral sheath insertions for coronary angiography in 1923 consecutive patients.

\section{Material and methods}

\section{Patient population}

All patients ( $n=1923)$ who underwent coronary angiography (CAG) from a femoral access site from July to December 2014 in our hospital received the FVCD after the examination had been completed. At that time, the transfemoral route was still the preferred way of vascular access in our center. We recorded all vascular events requiring further manual, interventional or surgical treatment from the time point of CAG until 2 months thereafter. Our hospital is the only center in the region of North Tyrol (approximately 10,600 $\mathrm{km}^{2}$, 620,000 inhabitants) that offers invasive coronary diagnostics and thus can warrant a reliable clinical follow-up also in retrospective clinical trials. After deployment of the FVCD, all patients received a compression bandage and had to lie in bed with an upper body elevation of not more than $30^{\circ}$ for $6 \mathrm{~h}$.

\section{FVCD device}

The VCD used in our trial was the FemoSeal ${ }^{\text {TM }}$ system manufactured by St. Jude Medical (Plymouth, MN, USA). The FemoSeal ${ }^{\mathrm{TM}}$ system can close an arterial puncture of the femoral artery using two resorbable polymer discs connected by a resorbable multifilament. The discs cover the arteriotomy and thus achieve mechanical hemostasis. A detailed description is available from the manufacturer and has previously been published [6].

\section{Study design}

Our investigation was performed as an investigatorinitiated retrospective single-center trial.

\section{Endpoints}

The primary endpoint was the incidence of complications at the femoral access site after FVCD administration, i.e. any bleeding with need of manual compression or FemoStop ${ }^{\mathrm{TM}}$ administration, pseudoaneurysm (PA), arteriovenous fistula (AVF), local infection or ipsilateral leg ischemia. Bleeding with need for additional compression was defined as any ongoing clinical signs of hemorrhage (palpable subcutaneous swelling/hematoma or bleeding from the puncture site) after deployment of the FVCD. Arterial PA were treated if the diameter exceeded $1 \mathrm{~cm}$. Ultrasound-guided thrombin injection served as first line treatment for arterial PAs. Patients with unfavorable anatomy (as assessed by an angiologist) or unsuccessful thrombin injection were referred to vascular surgery. Arteriovenous fistulas were regarded as relevant if a typically altered blood flow profile was detected in the ipsilateral common femoral vein together with an increase of blood flow of at least $200 \mathrm{ml} / \mathrm{min}$ as compared to the contralateral vein. Local infection was defined as any purulent inflammation at the puncture site. Ipsilateral leg ischemia was defined as acute leg ischemia after FCVD deployment or symptoms of a peripheral arterial occlusive disease stadium $2 \mathrm{~b}$ or higher.

Secondary endpoints were the occurrence of vascular complications in patient subgroups with preexisting peripheral artery disease (PAD), acute coronary syndrome on admission or the readministration of the FVCD within 90 days at the same puncture site. Other subgroups for secondary analyses received P2Y12 blockers, heparin, bivalirudin or glycoprotein (GP) IIb/IIIa inhibitors.

\section{Outcome assessment}

Outcomes were closely recorded when occurring during and after the patients' index procedure or when patients were readmitted due to access site complications. For this purpose electronic patient files comprising the period from July 2014 to February 2015 were investigated by two independent investigators.

\section{Interventional operators and method of access}

The team of operators consisted of 14 cardiologists with an approximate mean interventional experience 
Table 1 Baseline clinical and demographic patient characteristics

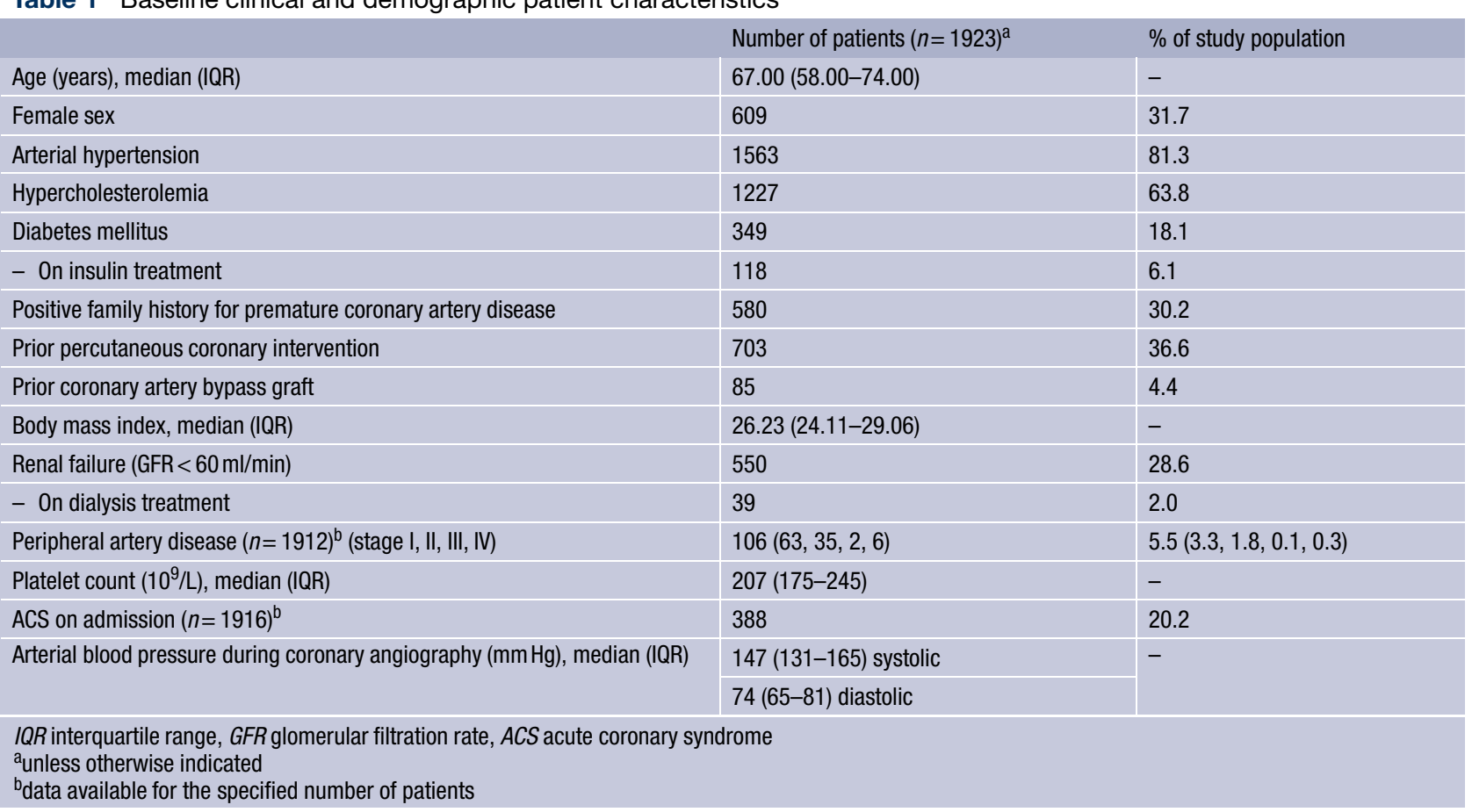

of 11.3 years. All operators used the landmark technique for determining the optimal femoral access point.

\section{Statistical analysis}

We used Graph Pad Prism version 7.01 (GraphPad Software, Inc., La Jolla, CA, USA) for statistical calculations. Fisher's exact test was used to investigate the impact of pre-existing conditions on the occurrence of vascular complications. A value of $p<0.05$ was considered statistically significant.

\section{Approval of the ethics committee}

This retrospective analysis has been approved by the Ethics Committee of the Medical University of Innsbruck, Austria (AN2015-0244 354/4.13). Due to the retrospective study design, obtaining a written informed consent from the patients was not regarded necessary by the ethics committee. The trial has been performed in accordance with the ethical standards laid down in the 1964 Declaration of Helsinki.

\section{Results}

\section{Baseline clinical and demographic patient characteristics}

A total of 1923 patients were investigated during this study. Table 1 summarizes the clinical and baseline characteristics. The mean age of the study patients was 67 years, $31.7 \%$ were female. Presence of cardiovascular risk factors was common in our population: arterial hypertension (81.3\%), hypercholesterolemia (63.8\%), diabetes mellitus (18.1\%), positive family history for premature cardiovascular diseases (30.2\%) and chronic renal failure $(28.6 \%)$. More than $20 \%$ of our study patients were admitted for CAG due to an acute coronary syndrome. Regarding periprocedural anticoagulation and antiplatelet therapy (AA), 1501 (78.3\%) of the patients received acetylsalicylic acid, 914 (47.8\%) were under treatment with P2Y12 receptor blockers, 261 (13.6\%) were orally anticoagulated and $909(47.5 \%)$ received other medication increasing the risk of bleeding at the time of CAG (Table 2). In total, 1325 patients $(68.9 \%)$ received a 6 French $(F)$ femoral catheter sheath, 598 patients $(31.1 \%)$ received a $7 \mathrm{~F}$ sheath. We used $7 \mathrm{~F}$ sheaths for percutaneous coronary intervention (PCI) of more complex lesions (e.g. bifurcations) and for the treatment of patients presenting with an acute coronary syndrome. In general, we already used $7 \mathrm{~F}$ sheaths for coronary diagnostics in patients presenting with acute coronary syndrome due to the associated high probability for the need of a subsequent PCI to avoid a time-consuming sheath exchange (from 6 to $7 \mathrm{~F}$ ) in case of a complex coronary lesion.

Demographics as well as presence of cardiovascular risk factors were comparable to study populations investigated in previous, randomized clinical trials [3, $6]$.

\section{Clinical outcome}

The primary endpoint occurred in 89 patients (4.6\%). Access site-related bleeding after deployment of the FVCD could be controlled with manual compression 
Table 2 Antithrombotic medication and anticoagulation before administration of femoral closure device

Table 3 Outcomes within 56 days after administration of femoral closure device

\begin{tabular}{|c|c|c|}
\hline & Number of patients & $\%$ of study population \\
\hline Acetylsalicylic acid $(n=1916)^{1}$ & 1501 & 78.3 \\
\hline P2Y12 receptor blocker $(n=1915)^{\mathrm{a}}$ & 914 & 47.8 \\
\hline - Clopidogrel & 575 & 30.0 \\
\hline - Prasugrel & 147 & 7.7 \\
\hline - Ticagrelor & 192 & 10.0 \\
\hline Oral anticoagulation $(n=1913)^{\mathrm{a}}$ & 261 & 13.6 \\
\hline - Vitamin $\mathrm{K}$ antagonists & 86 & 4.5 \\
\hline - Rivaroxaban & 127 & 6.6 \\
\hline - Dabigatran & 15 & 0.8 \\
\hline - Apixaban & 33 & 1.7 \\
\hline Others $(n=1915)^{\mathrm{a}}$ & 909 & 47.5 \\
\hline - Tirofiban & 14 & 0.7 \\
\hline - Abciximab & 50 & 2.6 \\
\hline - Heparin & 770 & 40.2 \\
\hline - Bivalirudin & 75 & 3.9 \\
\hline
\end{tabular}

\begin{tabular}{|c|c|c|}
\hline & Number of patients $(n=1923)$ & $\%$ of study population \\
\hline $\begin{array}{l}\text { Access site-related bleeding with need of manual com- } \\
\text { pression }\end{array}$ & 30 & 1.6 \\
\hline $\begin{array}{l}\text { Access site-related bleeding with need of FemoStop }{ }^{\mathrm{TM}} \\
\text { administration }\end{array}$ & 21 & 1.1 \\
\hline Pseudoaneurysm & 44 & 2.3 \\
\hline - Manual compression & 25 & 1.3 \\
\hline - Fibrin coagulation & 7 & 0.4 \\
\hline - Surgical treatment & 12 & 0.6 \\
\hline Arteriovenous fistula with surgical treatment & 1 & 0.05 \\
\hline Local infection & 0 & - \\
\hline Ipsilateral leg ischemia & 0 & - \\
\hline $\begin{array}{l}\text { Any bleeding with need of manual compression or } \\
\text { FemoStop } \\
\text { ovenous administration, pseudoaneurysm, arteri- } \\
\text { oventa, local infection or ipsilateral leg ischemia }\end{array}$ & 89 & 4.6 \\
\hline
\end{tabular}

in 30 patients $(1.6 \%)$ or use of the FemoStop ${ }^{\mathrm{TM}}$ system in 21 patients (1.1\%). Other access site-related complications were documented in 44 patients $(2.3 \%$, PA) and 1 patient $(0.05 \%$, AVF with need for surgical treatment). Local infections occurred in none of the patients. Importantly, we did not see a case of ipsilateral lower limb ischemia (Table 3).

In our subgroup analyses the presence of an acute coronary syndrome on admission increased the risk for developing postinvasive PA (4.4\% vs. $1.8 \%$, $p<0.01)$. The presence of a PAD did not significantly affect the risk for vascular access site complications $(p=0.20)$. Also, the readministration of the FVCD within 90 days at the same femoral artery, which occurred in 117 patients, did not increase the risk for vascular complications (Table 4 ).

Pharmacological pretreatment of the patients with P2Y12 blockers (3.5\% vs. $1.2 \%, p<0.01)$ or anticoagulants (heparin or bivalirudin, $3.3 \%$ vs. $1.5 \%, p<0.01$ ) increased the risk for developing PA but did not compromise the primary hemostasis mediated by the FVCD (Table 5). The need for additional compression after deployment of the FVCD (manual compression or using the FemoStop ${ }^{\mathrm{TM}}$ system) was neither increased in patients with increased vascular risk (PAD, ACS, readministration of FVCD, Table 4) nor in subjects with a pharmacologically increased risk for bleeding (antiplatelet therapy, anticoagulation). In further detailed analyses we could detect a numerically higher number of PAs in patients with an ACS in the cohort of anticoagulated patients (4.9\% vs. $2.4 \%$, $p=0.07$ ). We could also observe a numerically higher number of PAs in patients receiving anticoagulants in the cohort of non-ACS patients $(2.5 \%$ vs. $1.3 \%$, $p=0.11$ ). Both observations were not statistically significant (Table 5).

\section{Discussion}

In this retrospective analysis of patients receiving the FVCD without a prior femoral angiography, we could demonstrate that local vascular complications, i.e. any bleeding with additional need for manual compression or FemoStop ${ }^{\mathrm{TM}}$ administration, PA, AVF, 
Table 4 Subgroup analysis of vascular preconditions

\begin{tabular}{|c|c|c|c|c|c|}
\hline & $\begin{array}{l}\text { Number of patients } \\
\text { with pre-existing } \\
\text { condition }\end{array}$ & $\%$ of population & $\begin{array}{l}\text { Number of patients } \\
\text { without pre-existing } \\
\text { condition }\end{array}$ & $\%$ of study population & $p$-value \\
\hline Peripheral artery disease $(n=1912)^{\mathrm{a}}$ & 106 & - & 1806 & - & - \\
\hline $\begin{array}{l}\text { - Access site-related bleeding with need for } \\
\text { compression (manual or FemoStop }\end{array}$ & 5 & 4.7 & 46 & 2.5 & 0.20 \\
\hline - Pseudoaneurysm & 0 & 0 & 44 & 2.4 & 0.17 \\
\hline $\begin{array}{l}\text { Acute coronary syndrome on admission } \\
(n=1916)^{\mathrm{a}}\end{array}$ & 388 & - & 1528 & - & - \\
\hline $\begin{array}{l}\text { - Access site-related bleeding with need for } \\
\text { compression (manual or FemoStop }{ }^{\top M} \text { ) }\end{array}$ & 11 & 2.8 & 40 & 2.6 & 0.86 \\
\hline - Pseudoaneurysm & 17 & 4.4 & 27 & 1.8 & $<0.01$ \\
\hline $\begin{array}{l}\text { Readministration of the femoral closure de- } \\
\text { vice within } 90 \text { days at same puncture site } \\
(n=1920)^{\mathrm{a}}\end{array}$ & 117 & - & 1803 & - & - \\
\hline $\begin{array}{l}\text { - Access site-related bleeding with need for } \\
\text { compression (manual or FemoStop }\end{array}$ & 1 & 0.9 & 50 & 2.7 & 0.37 \\
\hline - Pseudoaneurysm & 2 & 1.7 & 42 & 2.3 & 1.00 \\
\hline
\end{tabular}

local infection or ipsilateral leg ischemia, occurred in $4.6 \%$ of our patients. The vascular complication rate was largely comparable to the number of complications reported in a large-scale randomized clinical trial (ISAR-CLOSURE) which, in contrast to our trial, performed femoral angiography prior to FVCD deployment as recommended by the manufacturer [3]. Due to the different study designs, endpoint definitions could not be completely matched in both trials; however, we were able to demonstrate that using the FVCD without prior angiography is relatively safe. This may help to reduce radiation exposure for physicians and to diminish use of contrast agent. Furthermore, major vascular complication rates were comparably low. Our study included all clinically relevant endpoints which make the study results of both trials largely comparable.

\section{Pseudoaneurysms}

Compared to the trial by Schulz-Schupke et al. we observed a slightly higher number of PA in our study population [3]. This may be based on the fact that our all-comers population partially presented in an acute clinical setting (20.2\% of patients). In contrast to patients presenting with stable angina pectoris, ACS treatment comprised the predominant use of $7 \mathrm{~F}$ catheter sheaths as well as administration of anticoagulants and antiplatelet therapy. Both the presence of ACS as well as administration of anticoagulants led to an increase in PA formation. Administration of oral P2Y12 inhibitors also increased the rate of femoral pseudoaneurysms. The PAs occurred in more than $3 \%$ of our patients that were treated with any P2Y12 blocker, heparin/bivalirudin or a GP IIb/IIIa inhibitor. This reflects the fact that AA can lead to a persistent minor hemorrhage at the femoral puncture site after use of a VCD [1]. Patients not treated with AA therapy in our population as well as in the ISAR-CLOSURE trial showed a significantly lower PA rate of $1.3 \%$ and $1.8 \%$, respectively [3].

We saw a numerical increase of PA in the setting of ACS when only patients receiving anticoagulants were observed. Likewise, we could detect a trend towards increased numbers of PA in patients receiving anticoagulants when only patients without ACS were observed. Although not significant, both observations support the hypothesis that the presence of ACS as well as administration of anticoagulants increase the risk of PA formation independent from each other. While heparin administration might increase the risk of bleeding at the site of sheath introduction, we can speculate that the setting of ACS might lead to an increased number of PAs due to inaccurate arterial puncture or restless patients in emergency situations. Due to a huge overlap in patient subgroups receiving $7 \mathrm{~F}$ sheaths, presenting with ACS or receiving anticoagulants, we were not able to identify the use of $7 \mathrm{~F}$ sheaths as an independent risk factor for the development of arterial PA; however, although the deployment of the FVCD is safe to seal $7 \mathrm{~F}$ puncture sites [7], we cannot exclude that the larger sheath diameter did have an impact on PA formation.

\section{External compression}

The AA treatment did not adversely affect primary hemostasis, i.e. the need for additional external compression (manual compression or using the FemoStop $^{\mathrm{TM}}$ device) immediately after deployment of the FVCD. Corresponding to our results, another randomized clinical trial, the CLOSE-UP study, showed comparably low numbers of vascular complications after FVCD deployment without prior femoral angiography [6]. Thus, regarding the integrity of the femoral arterial wall, we can summarize that deploy- 
Table 5 Subgroup analyses of pharmacological preconditions

\begin{tabular}{|c|c|c|c|c|c|}
\hline & $\begin{array}{l}\text { Number of patients with } \\
\text { pre-existing condition }\end{array}$ & $\%$ of population & $\begin{array}{l}\text { Number of patients } \\
\text { without pre-existing } \\
\text { condition }\end{array}$ & $\begin{array}{l}\% \text { of study } \\
\text { population }\end{array}$ & $p$-value \\
\hline $\begin{array}{l}\text { Administration of P2Y12 receptor blockers } \\
(n=1915)^{1}\end{array}$ & 914 & - & 1001 & - & - \\
\hline $\begin{array}{l}\text { - Access site-related bleeding with need for } \\
\text { compression (manual or FemoStop }\end{array}$ & 21 & 2.3 & 30 & 3.0 & 0.39 \\
\hline - Pseudoaneurysm & 32 & 3.5 & 12 & 1.2 & $<0.01$ \\
\hline Administration of heparin or bivalirudin $(n=1915)^{\mathrm{a}}$ & 845 & - & 1070 & - & - \\
\hline $\begin{array}{l}\text { - Access site-related bleeding with need for } \\
\text { compression (manual or FemoStop }\end{array}$ & 22 & 2.6 & 29 & 2.7 & 1.00 \\
\hline - Pseudoaneurysm & 28 & 3.3 & 16 & 1.5 & $<0.01$ \\
\hline $\begin{array}{l}\text { Patients with ACS in the cohort of patients receiv- } \\
\text { ing heparin or bivalirudin }(n=845)\end{array}$ & 304 & - & 541 & - & - \\
\hline $\begin{array}{l}\text { - Access site-related bleeding with need for } \\
\text { compression (manual or FemoStop }\end{array}$ & 7 & 2.3 & 14 & 2.6 & 1.00 \\
\hline - Pseudoaneurysm & 15 & 4.9 & 13 & 2.4 & 0.07 \\
\hline $\begin{array}{l}\text { Administration of heparin or bivalirudin in the } \\
\text { cohort of patients without ACS }(n=1528)\end{array}$ & 552 & - & 976 & - & - \\
\hline $\begin{array}{l}\text { - Access site-related bleeding with need for } \\
\text { compression (manual or FemoStop }\end{array}$ & 14 & 2.5 & 26 & 2.6 & 1.00 \\
\hline - Pseudoaneurysm & 14 & 2.5 & 13 & 1.3 & 0.11 \\
\hline Administration of GP IIb/Illa inhibitors $(n=1915)^{\mathrm{a}}$ & 64 & - & 1851 & - & - \\
\hline $\begin{array}{l}\text { - Access site-related bleeding with need for } \\
\text { compression (manual or FemoStop }\end{array}$ & 1 & 1.6 & 50 & 2.7 & 1.00 \\
\hline - Pseudoaneurysm & 4 & 6.2 & 40 & 2.2 & 0.06 \\
\hline $\begin{array}{l}\text { Administration of any P2Y12 blocker, heparin/ } \\
\text { bivalirudin or GP IIb/Illa inhibitor }(n=1911)^{\mathrm{a}}\end{array}$ & 1063 & - & 848 & - & - \\
\hline $\begin{array}{l}\text { - Access site-related bleeding with need for } \\
\text { compression (manual or FemoStop }\end{array}$ & 29 & 2.7 & 22 & 2.6 & 0.89 \\
\hline - Pseudoaneurysm & 33 & 3.1 & 11 & 1.3 & $<0.01$ \\
\hline $\begin{array}{l}\text { Administration of any P2Y12 blocker (prasugrel/ } \\
\text { ticagrelor vs. clopidogrel) }(n=914)\end{array}$ & 339 (prasugrel/ticagrelor) & - & 575 (Clopidogrel) & - & - \\
\hline $\begin{array}{l}\text { - Access site-related bleeding with need for } \\
\text { compression (manual or FemoStop }\end{array}$ & 8 & 2.4 & 13 & 2.3 & 1.0 \\
\hline - Pseudoaneurysm & 6 & 1.8 & 22 & 3.8 & 0.11 \\
\hline
\end{tabular}

ment of the FVCD appears to be safe without prior angiography of the punctured artery.

\section{Ischemic events}

Beside hemorrhagic complications, the use of VCDs bears the risk for induction of vascular stenoses or occlusions as well as embolization of the closure device. We did not see a single ischemic vascular event that had to be treated surgically or interventionally after deployment of the FVCD. These results are in line with both the CLOSE-UP and the ISAR-CLOSURE trials that did not report any ischemic events in the lower limb after FVCD deployment, as well $[3,6]$.

\section{Limitations}

The major limitation of our trial is the retrospective analysis of clinical data routinely recorded from the patients referred to coronary angiography and angioplasty in our hospital. We therefore did not quantify hematomas or vascular complications that did not lead to interventional or surgical treatment. The study design also comprises the fact that we were not able to compare our data to a fully matched control population. Although our baseline and demographic patient characteristics well reflect the typical western patients suffering from coronary artery disease, certain differences to comparable populations from randomized trials still exist. We notably included patients suffering from ACS who were not represented in the two available large randomized clinical trials [3, 6]; however, non-ACS patients in our population showed the same rates of PA as compared to the ISAR-CLOSURE trial $(1.8 \%)$. A final consideration of risks and benefits of omitting the femoral angiography prior to FVCD deployment can only be determined in a future randomized clinical trial. 


\section{Conclusion}

Large-scale randomized trials have only investigated the use of the FemoSeal ${ }^{\mathrm{TM}}$ device in patients receiving diagnostic coronary angiography using a $6 \mathrm{~F}$ sheath. Patients presenting with ACS, undergoing PCI or receiving anticoagulants have been excluded from all of these studies $[3,6]$.

In this retrospective analysis, we could now show that omitting femoral angiography prior to the deployment of the FemoSeal ${ }^{\mathrm{TM}}$ system appears to be safe in an all-comers population undergoing diagnostic coronary angiography and PCI with stable angina pectoris or acute coronary syndrome using catheter sheaths up to a size of $7 \mathrm{~F}$. The overall complication rates were comparable to those seen in the studies mentioned above.

While FemoSeal ${ }^{\mathrm{TM}}$ reimplantation at the same site during a time frame of 90 days as well as the presence of a PAD did not affect the rate of vascular complications, we could see that patients undergoing PCI for the treatment of an ACS or stable angina showed increased numbers of arterial PA. This supports the current guideline recommendations for a preferred use of the radial access route, especially in situations with an increased risk of bleeding [8-10].

Acknowledgements We want to thank our technicians and nurses in the catheterization laboratory and on the wards of our Department of Cardiology and Angiology, Medical University of Innsbruck, Austria for their help in treating our patients.

Funding Open access funding provided by University of Innsbruck and Medical University of Innsbruck.

Conflict of interest C. Brenner received compensation for travel expenses (participation fee for a scientific conference) from St. Jude Medical. J. Margreitter, A. Gratl, J. Klocker, R. Kirchmair, P. Marschang, G. Friedrich, B. Metzler, and N. Moes declare that they have no competing interests.

Open Access This article is distributed under the terms of the Creative Commons Attribution 4.0 International License (http://creativecommons.org/licenses/by/4.0/), which permits unrestricted use, distribution, and reproduction in any medium, provided you give appropriate credit to the original author(s) and the source, provide a link to the Creative Commons license, and indicate if changes were made.

\section{References}

1. Alonzo A, Rigattieri S, Giovannelli F, Di Russo C, Sciahbasi A, Berni A, et al. Transfemoral approach with systematic use of FemoSeal closure device compared to transradial approach in primary angioplasty. Catheter Cardiovasc Interv. 2015; https://doi.org/10.1002/ccd.26076.

2. Tavris DR, WangY, JacobsS, Gallauresi B, Curtis J, Messenger $\mathrm{J}$, et al. Bleeding and vascular complications at the femoral access site following percutaneous coronary intervention (PCI): an evaluation of hemostasis strategies. J Invasive Cardiol. 2012;24(7):328-34.

3. Schulz-Schupke S, Helde S, Gewalt S, Ibrahim T, Linhardt $\mathrm{M}$, Haas $\mathrm{K}$, et al. Comparison of vascular closure devices vs manual compression after femoral artery puncture: the ISAR-CLOSURE randomized clinical trial. JAMA. 2014;312(19):1981-7.

4. Cox T, Blair L, Huntington C, Lincourt A, Sing R, Heniford BT. Systematic review of randomized controlled trials comparing manual compression to vascular closure devices for diagnostic and therapeutic arterial procedures. Surg Technol Int. 2015;27:32-44.

5. Medical SJ. FemoSeal(TM) Vascular Closure Systeminstructions for use. 2014. pp.9-17.

6. Holm NR, Sindberg B, Schou M, Maeng M, Kaltoft A, Bottcher M, et al. Randomised comparison of manual compression and FemoSeal vascular closure device for closure after femoral artery access coronary angiography: the CLOSure dEvices Used in everyday Practice (CLOSEUP) study. EuroIntervention. 2014;10(2):183-90.

7. Wanitschek MM, Suessenbacher A, Dorler J, Pachinger O, Moes N, Alber HF. Safety and efficacy of femoral artery closure with the FemoSeal(R) device after coronary angiographyusing a 7 French sheath. Perfusion. 2011;26(5):447-52.

8. Windecker S, Kolh P, Alfonso F, Collet JP, Cremer J, Authors/ Task Force m, Authors/ Task Force m. 2014 ESC/ EACTS guidelines on myocardial revascularization: the task force on myocardial revascularization of the European society of cardiology (ESC) and the European association for cardio-thoracic surgery (EACTS) developed with the special contribution of the European association of percutaneous cardiovascular interventions (EAPCI). Eur Heart J. 2014;35(37):2541-619.

9. Roffi M, Patrono C, Collet JP, Mueller C, Valgimigli M, Andreotti F, et al. 2015 ESC guidelines for the management of acute coronary syndromes in patients presenting without persistentST-segment elevation: taskforcefor themanagement of acute coronary syndromes in patients presenting without persistent ST-segment elevation of the European society of cardiology (ESC). Eur Heart J. 2016;37(3):267-315.

10. Ibanez B, James S, Agewall S, Antunes MJ, Bucciarelli-Ducci $\mathrm{C}$, Bueno $\mathrm{H}$, et al. $2017 \mathrm{ESC}$ guidelines for the management of acute myocardial infarction in patients presenting with ST-segment elevation. Eur Heart J. 2017; https://doi.org/ 10.1093/eurheartj/ehx393. 